\title{
Antibacterial, Anti-biofilm Activity of Some Non-steroidal Anti-Inflammatory Drugs and N-acetyl Cysteine against Some Biofilm Producing Uropathogens
} \author{
Rehab Mahmoud Abd El-Baky ${ }^{4, *}$ \\ ${ }^{1}$ Undergraduate student, faculty of pharmacy, Minia University \\ ${ }^{2}$ Undergraduate student, Faculty of science, Minia University \\ ${ }^{3}$ Demonstrator of microbiology, Faculty of Pharmacy, Minia University \\ ${ }^{4}$ Lecturer of microbiology, Faculty of Pharmacy, Minia University \\ *Corresponding author: dr_rehab010@yahoo.com
}

Ahmed Mohsen ${ }^{1}$, Alyaa Gomaa ${ }^{1}$, Fatma Mohamed ${ }^{1}$, Roaa Ragab ${ }^{1}$, mennatallah Eid ${ }^{1}$, Al-Hussein Ahmed ${ }^{2}$, Areej Khalaf ${ }^{2}$, Mohamed Kamal $^{1}$, Safaa Mokhtar ${ }^{1}$, Hadeer Mohamed ${ }^{1}$, Islam Salah ${ }^{1}$, Rania Abbas ${ }^{1}$, Sameh Ali $^{3}$,

Received December 26, 2014; Revised January 02, 2015; Accepted January 06, 2015

\begin{abstract}
Ureteral catheters are indispensable devices used in the management of ureteral obstruction. Although the stent is essential for treatment, it also has complications, which are encrustation, stone formation and biofilm formation. Biofilm infections result in a complication in the course of treatment, increasing the length of patients stay in hospital and overall cost. Catheter-associated infections are difficult to be treated with antibiotics and there is a need to change catheters due to the formation of biofilm on their surfaces. In this study, In this study, we examine the effect of some of prescribed drugs as NSAIDs and N-acetylcysteine on the adherence of S. aureus, K. pneumoniae, P. aeruginosa and Proteus mirabilis on the surface of catheters, and their effects on the preformed mature biofims. Also, we determine their antibacterial activity. The results showed that the tested agents had good antibacterial activity, a significant effect on the inhibition of adherence of the tested strains to plastic surfaces and a high disruptive effect on mature biofilms. In conclusion, the tested drugs can be used in the treatment of catheterassociated infections.
\end{abstract}

Keywords: NSAIDs, biofilm, mucolytics, adherence

Cite This Article: Ahmed Mohsen, Alyaa Gomaa, Fatma Mohamed, Roaa Ragab, mennatallah Eid, Al-Hussein Ahmed, Areej Khalaf, Mohamed Kamal, Safaa Mokhtar, Hadeer Mohamed, Islam Salah, Rania Abbas, Sameh Ali, and Rehab Mahmoud Abd El-Baky, "Antibacterial, Anti-biofilm Activity of Some Non-steroidal Anti-Inflammatory Drugs and N-acetyl Cysteine against Some Biofilm Producing Uropathogens.” American Journal of Epidemiology and Infectious Disease, vol. 3, no. 1 (2015): 1-9. doi: 10.12691/ajeid-3-1-1.

\section{Introduction}

Bacterial biofilms can be defined as microbe-derived sessile communities attached to a surface and embedded in a self produced matrix of polymers. These biofilm bacteria show a different metabolic state than planktonic bacteria, especially with respect to transcription and cell interactions [1,2]. Biofilm-forming organisms are often more resistant to high levels of antimicrobial agents than the planktonic cells, which makes bacterial eradication difficult to achieve despite the use of in vitro active antibiotics $[3,4,5,6]$. It seems that biofilm-embedded bacteria enter in a stationary state, driving to physicochemical interactions with production of slime, followed by lower diffusion of active molecules, and then a lesser susceptibility to antimicrobial killing [7]. Medical and environmental impact of microbial biofilm has led to an expanding investigation of the biology and regulatory mechanisms of biofilm formation and dispersal $[8,9]$.
Strategies have been proposed to inhibit biofilm formation by using different drugs both in solution and applied to some medical devices [10,11,12,13].

Catheter-associated infections are difficult to be treated with antibiotics and there is a need to change catheters due to the formation of biofilm on their surfaces. In recent years, due to the increased resistance of many bacteria to the commonly used antimicrobial agents, attention has shifted to drugs belonging to different pharmacological classes for possible antimicrobial activity. Many studies showed that NSAIDs have antibacterial activity and decrease adherence and biofilm formation by bacteria. Unfortunately, one of the main side effects of NSAID administration is renal function damage. NSAID are accountable for $7 \%$ of all cases of acute renal failure and for $37 \%$ incidents of drug-associated acute renal failure [14]. Inhibition of prostaglandin synthesis by NSAID administration might lead to renal ischaemia, decline in glomerular hydraulic pressure and, consequently, to acute renal insufficiency $[15,16,17]$. Indeed, renal biopsies from patients with NSAID-induced acute renal failure disclose 
signs of acute tubular necrosis [14]. N-acetylcysteine (NAC) has been shown to effectively prevent nephrotoxicity induced by contrast media, hypoperfusion or in toxininduced renal failure in humans and experimental animals [18-23]. In addition, NAC is known to exert a vasodilatatory effect on renal microcirculation [24]. The operative mechanisms have not yet been fully elucidated. Thus far, the probability of NAC playing a role in prevention or attenuation of NSAID-induced acute renal failure has never been approached. NAC successfully attenuated the deterioration of renal function by inducing renal vasodilatation, decreasing oxidative stress via inhibition of intrarenal ROS content and, most importantly, restoration of intrarenal PGE2 release back to the normal levels [25]. So, we studied the effect of Three NSAIDs with and without $\mathrm{N}$-acetylcysteine on the adherence and Biofilm formation of some pathogens which may cause urinary tract infection.

\section{Mateirals and Methods}

\subsection{Microbial Strains}

Standard strains of S. aureus (ATCC 6538), K. pneumoniae (ATCC 10031), Ps. aeruginosa (ATCC 10145), were obtained from MIRCIN culture collection of the Faculty of Agriculture, Ain Shams University. Proteus mirabilis (clinical strain) was obtained from the department of microbiology and immunology, Faculty of Pharmacy, Minia university, Minia, Egypt.

\subsection{Biofilm Production}

The tested organisms were tested for their ability to form biofilm by Tissue Culture Plate method (TCP) [26].

\subsection{Evaluation of the Antibacterial Effect of the Tested Agents and the Determination of Their MIC using Agar Well Diffusion Method}

Microorganisms $(0.5 \mathrm{ml})$ of $1.5 \times 10^{8} \mathrm{CFU} / \mathrm{ml}(0.5$ Mcfarland turbidity) were plated in sterile petri dishes then $20 \mathrm{ml}$ of sterile, molten and cooled $\left(45^{\circ} \mathrm{C}\right)$ Muller Hinton agar media was added to all petri dishes. The plates then were rotated slowly to ensure uniform distribution of the microorganisms and then allowed to solidify on a flat surface. After solidification, four equidistant and circular wells of $10 \mathrm{~mm}$ diameter were carefully punched using a sterile cork bore. Two fold serial dilutions were performed on the tested NSAIDs and $\mathrm{N}$-acetyl cysteine. Equal volumes of each dilution were applied separately to each well in three replicates using a micropipette. All plates were incubated overnight at $37^{\circ} \mathrm{C}$, then collected and zones of inhibition that developed were measured. The average of the zones of inhibition was calculated. The minimum inhibitory concentration (MIC) was calculated by plotting the natural logarithm of the concentration of each dilution against the square of zones of inhibition. A regression line was drawn through the points. The antilogarithm of the intercept on the logarithm of concentration axis gave the MIC value [27].

2.4. Testing the Effect of the Tested Drugs on
the Adherence of the Tested Pathogens to
Plastic Surfaces by Crystal Violet Assay Method
All strains were first streaked on Muller Hinton agar media then, incubated at $25^{\circ} \mathrm{C}$ for $48 \mathrm{~h}$. A large loop of actively growing cells (for each strain) was transferred to sterile trypticase soy broth (TSB) (Difco Laboratories) containing $0.9 \%$ D-glucose. After incubation at $25^{\circ} \mathrm{C}$ for $24 \mathrm{~h}$, the cells were centrifuged and washed twice with 0.5 ml PBS (phosphate buffered saline), followed by vortexing and centrifugation at $5000 \mathrm{~g}$ for $5 \mathrm{~min}$. The washed cells were suspended in $1 \mathrm{ml}$ TSB broth and adjusted to a final OD600 nm value of 1.0 with TSB broth. These cell suspensions were then used to grow biofilms.

$100 \mu \mathrm{l}$ of the suspension (OD600) was inoculated into individual wells of polystyrene 96 -well plates (flat bottom; Nunc). TSB broth was used as a negative control. The plates were incubated at $25^{\circ} \mathrm{C}$ for 90 min (adhesion period). Supernatants including planktonic cells were discarded and wells were gently washed with PBS twice to remove any non-adherent cells. $100 \mu \mathrm{l}$ of fresh TSB broth containing MIC concentrations of each of the following solutions: NSAIDs (Ketoprofen, Ibuprofen, Sodium Diclofenac) and N-acetyl cysteine each alone and in combination was added to each well. The plates were covered to prevent evaporation and incubated at $25^{\circ} \mathrm{C}$ for $24 \mathrm{~h}$. Liquid media containing the non adherent cells were discarded through two rounds of washing with $200 \mu \mathrm{l}$ sterile PBS buffer. Adherent cells to the plastic surfaces were quantified using Crystal violet assay. Experiment was performed in triplicate.

\subsection{Testing Their Ability to Disrupt the Already Formed Mature Biofilms by Crystal Violet Assay Method}

$100 \mu \mathrm{l}$ of the suspension (OD600) was inoculated into individual wells of polystyrene 96 -well plates (flat bottom; Nunc). The plates were incubated at $25^{\circ} \mathrm{C}$ for $48 \mathrm{~h}$. After the incubation period, the supernatants from each well were aspirated and the wells washed twice with PBS without disturbing the biofilms at the bottom of the wells, $100 \mu \mathrm{l}$ of fresh TSB broth containing MIC concentrations of each of the following solutions: NSAIDs (Ketoprofen, Ibuprofen, Sodium Diclofenac) and N-acetyl cysteine each alone and in combination was added to each well. Normal saline without any agents was added to the control wells. The plates were incubated at $25^{\circ} \mathrm{C}$ for $24 \mathrm{~h}$. Supernatants were discarded through two rounds of washing with 200 $\mu \mathrm{l}$ sterile PBS saline. Cells adherent to the plastic surfaces were quantified using Crystal violet assay [28]. Experiment was performed in triplicate.

\subsection{Scanning Electron Microscopy (SEM)}

The untreated bacterial cells (control) and strains treated with the tested drugs were fixed in $2.5 \%$ (vol/vol) glutaraldehyde in Dulbecco PBS (PH 7.2) for $1.5 \mathrm{~h}$, rinsed with PBS, and then dehydrated through an ethanol series. Samples were dried and gold-palladium coated. SEM examinations were made on a JSM-840 SEM (JEOL Ltd., Tokyo, Japan) [29].

2.7. Effect of MICs of the Tested Agents on Motility of Ps. aeruginosa and Proteus mirabilis Cells 
Following 24-, 48- and 72-h incubation at $37{ }^{\circ} \mathrm{C}$ in the presence and absence of MICs of NSAIDs and NAC. Bacterial cells were centrifuged for $2 \mathrm{~min}$ at $2500 \mathrm{rpm}$ to separate the cells. Bacterial cells were washed three times with PBS. Bacterial culture was inoculated into the tube with Motility Agar. Control cultures contained no drugs [30].

\subsection{Statistical Analysis}

One-Way ANOVA as employed to evaluate any significant difference between the values obtained without the drug (controls) and the values obtained in the presence of different drug concentrations. Differences were done using SPSS, 17 statistical software (SPSS Inc., Chicago, IL).

\section{Results}

\subsection{Biofilm Production}

According to TCP method strains can be classified into weak adherent at OD $<0.120$, moderate $0.120-0.240$ and strong $>0.240$. It was found that $S$. aureus ATCC 6538 and Ps. aeruginosa ATCC 10145 were strong biofilm producers

Table 1. Ability of the tested microorganisms to produce biofilm

\begin{tabular}{|l|c|}
\hline Strains & Ability to adhere to TCP surface \\
\hline S. aureus (ATCC 6538) & Strong \\
\hline K. pneumoniae (ATCC 10031) & Moderate \\
\hline Ps. aeruginosa (ATCC 10145) & Strong \\
\hline Proteus mirabilis & Moderate \\
\hline
\end{tabular}

\subsection{Antibacterial Activity and MIC of the Tested Drugs against Microorganisms}

Ibuprofen showed the highest antibacterial and the lowest MIC against S. aureus, Ps. aeruginosa and Proteus mirabilis while Sodium diclofenac showed the highest activity against $K$. pneumoniae. The tested NSAIDs showed higher antibacterial activity than $\mathrm{N}$-acetylcysteine (Table 2).

Table 2. the Minimum inhibitory concentration of ketoprofen, Ibuprofen, Sodium diclofenac and N-acetyl cysteine

\begin{tabular}{|l|c|c|c|}
\hline \multirow{2}{*}{ Microorganisms } & \multicolumn{3}{|c|}{ MIC $(\mu \mathrm{g} / \mathrm{ml})$} \\
\cline { 2 - 5 } & ketoprofen & Ibuprofen & sod Diclofenac \\
\hline S. aureus (ATCC 6538) & 1607.5 & 952 & 1465 \\
\hline K. pneumoniae (ATCC 10031) & 1732.5 & 250 & 173.7 \\
\hline Ps. aeruginosa (ATCC 10145) & 1756.7 & 1292.2 & 1675.7 \\
\hline Proteus mirabilis & 1635.3 & 1465.4 & 2500 \\
\hline
\end{tabular}

\subsection{Effect of the Tested Drugs on the Adherence of Microorganisms}

Figure 1 and Figure 2 showed that $\mathrm{N}$-acetyl cysteine had a higher inhibitory effect on the adherence of $S$. aureus, K. pneumoniae and Proteus mirabilis in comparison to ketoprofen $(\mathrm{P}<0.05)$ and Sodium diclofenac $(\mathrm{P}<0.01)$. On the other hand, Ketoprofen showed a higher effect $(\mathrm{P}<0.05)$ on Ps. aeruginosa adherence than NAC. Their combination significantly inhibit the adherence of $(\mathrm{P}<0.05)$ all tested organisms in comparison to each drug and NAC alone. Ibuprofen and NAC combination showed a significant inhibitory effect $(\mathrm{P}<0.05)$ on adherence of the tested organisms in comparison to Ibuprofen but not significant in comparison to NAC (Figure 3). In addition, Ketoprofen showed a higher inhibitory effect on S. aureus, K. pneumoniae and Ps. aeruginosa compared to NSAIDs (Figure 4).

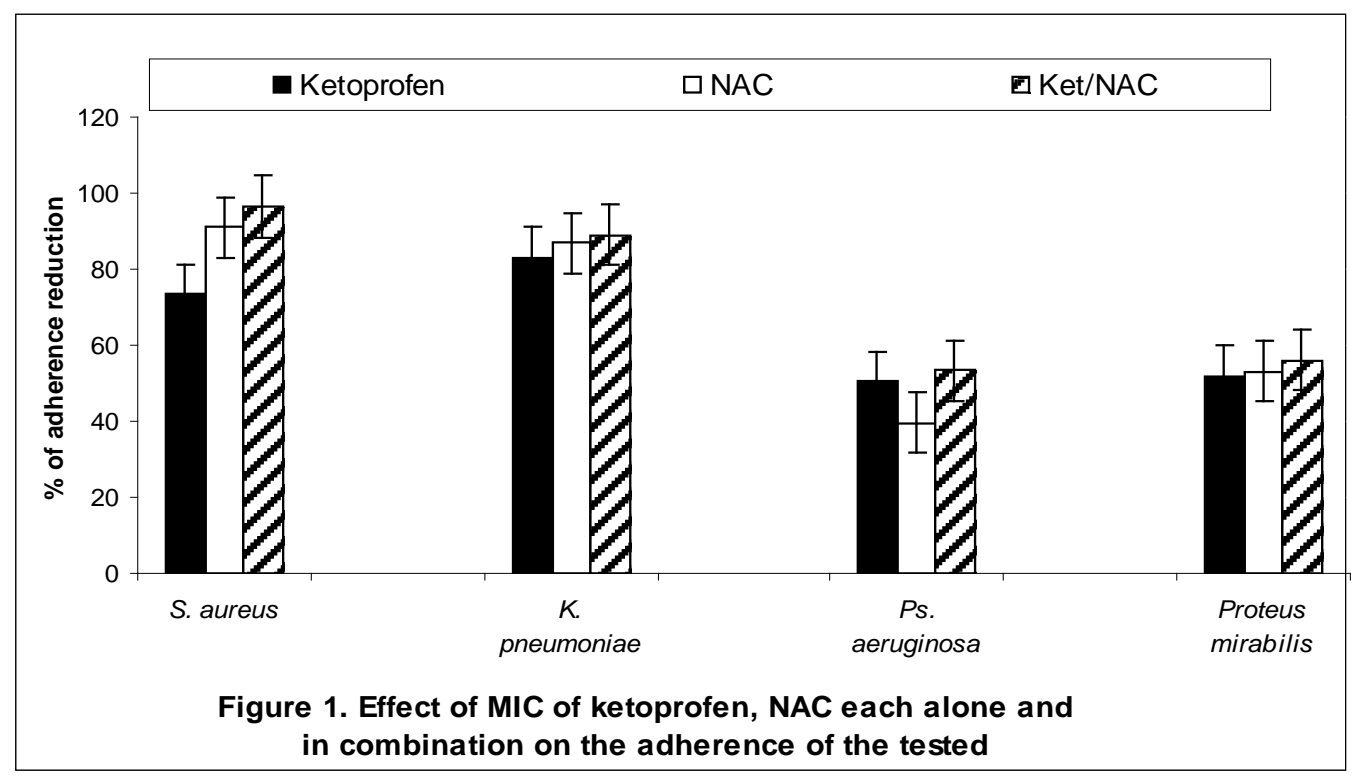

Figure 1. Effect of MIC of ketoprofen, NAC each alone and in combination on the adherence of the tested 


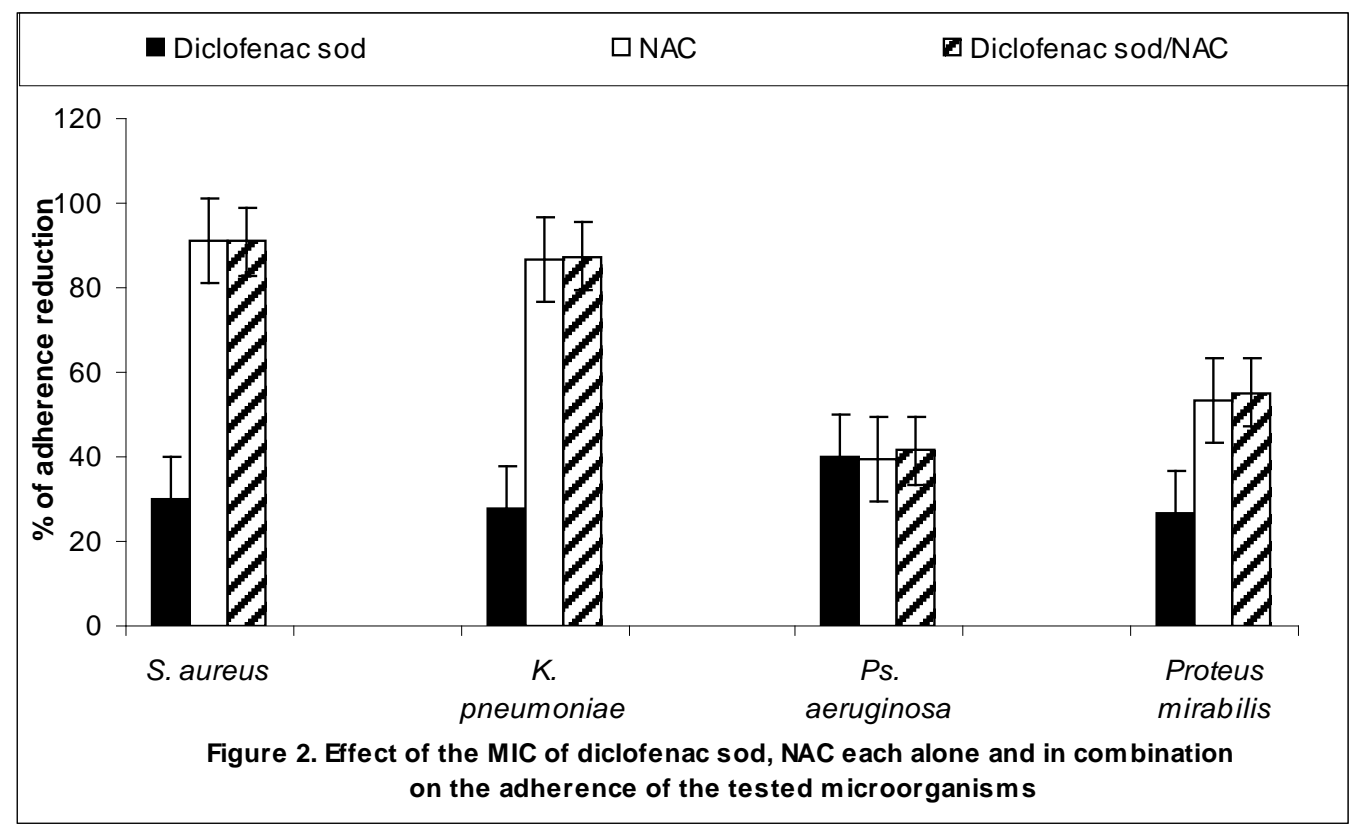

Figure 2. Effect of the MIC of diclofenac sod, NAC each alone and in combination on the adherence of the tested microorganisms

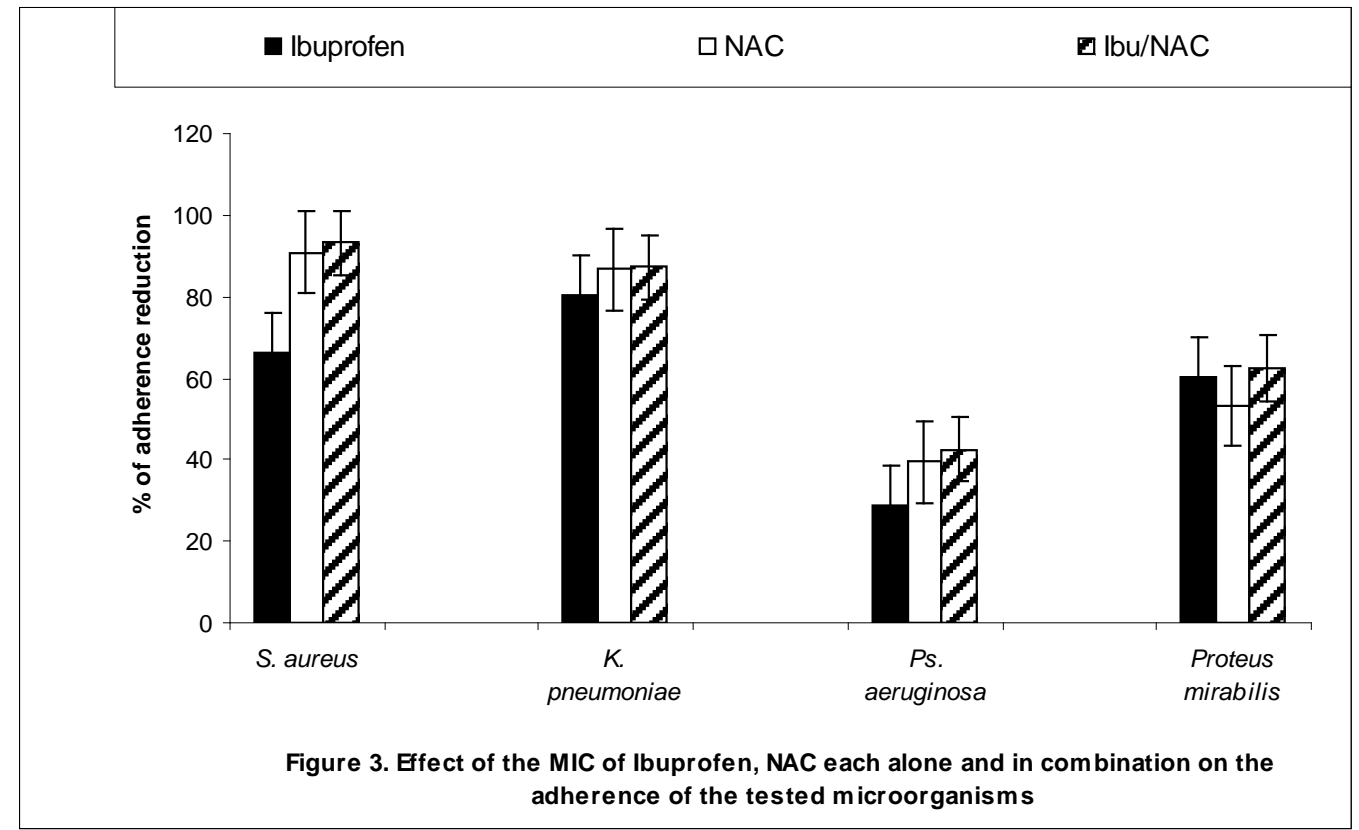

Figure 3. Effect of the MIC of ibuprofen, NAC each alone and in combination on the adherence of the tested microorganisms

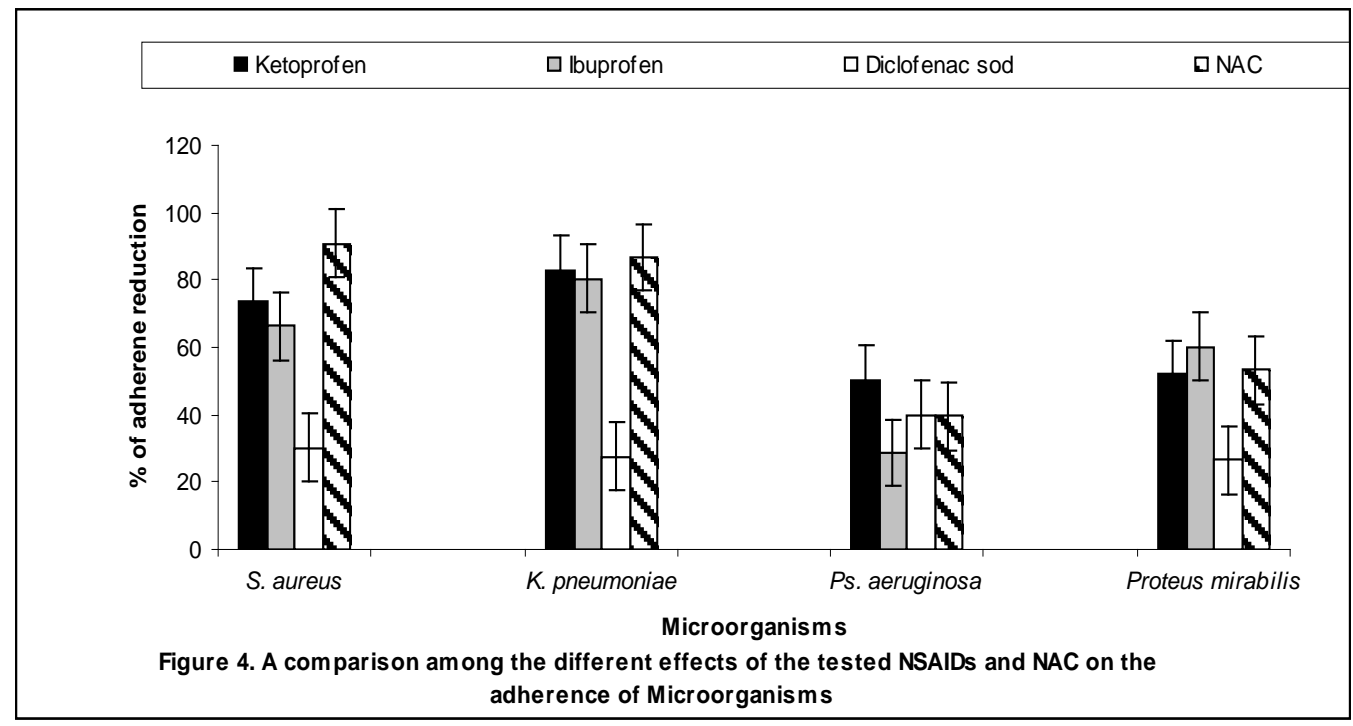

Figure 4. A comparison among the different effects of the tested NSAIDs and NAC on the adherence of Microorganisms 


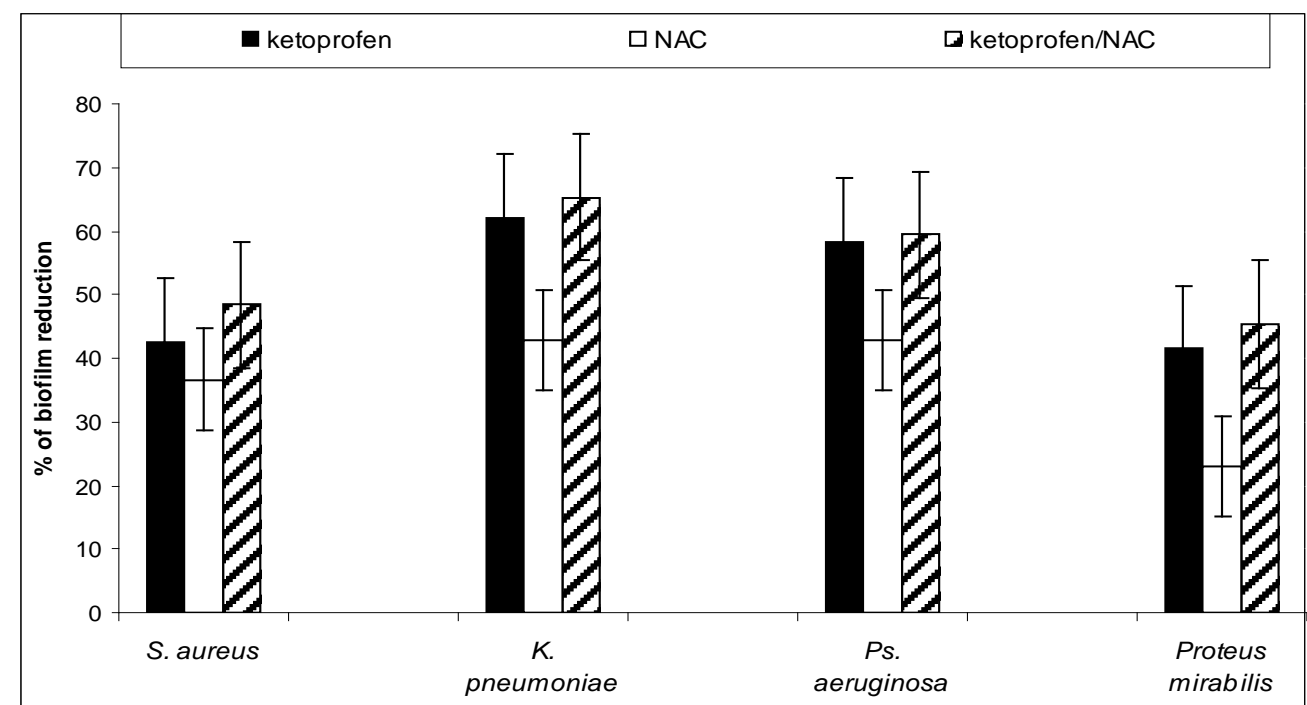

Figure 5. Effect of ketoprofen, NAC each alone and in combination on mature biofilms formed by the tested organisms

Figure 5. Effect of ketoprofen, NAC each alone and in combination on mature biofilms formed by tested organisms

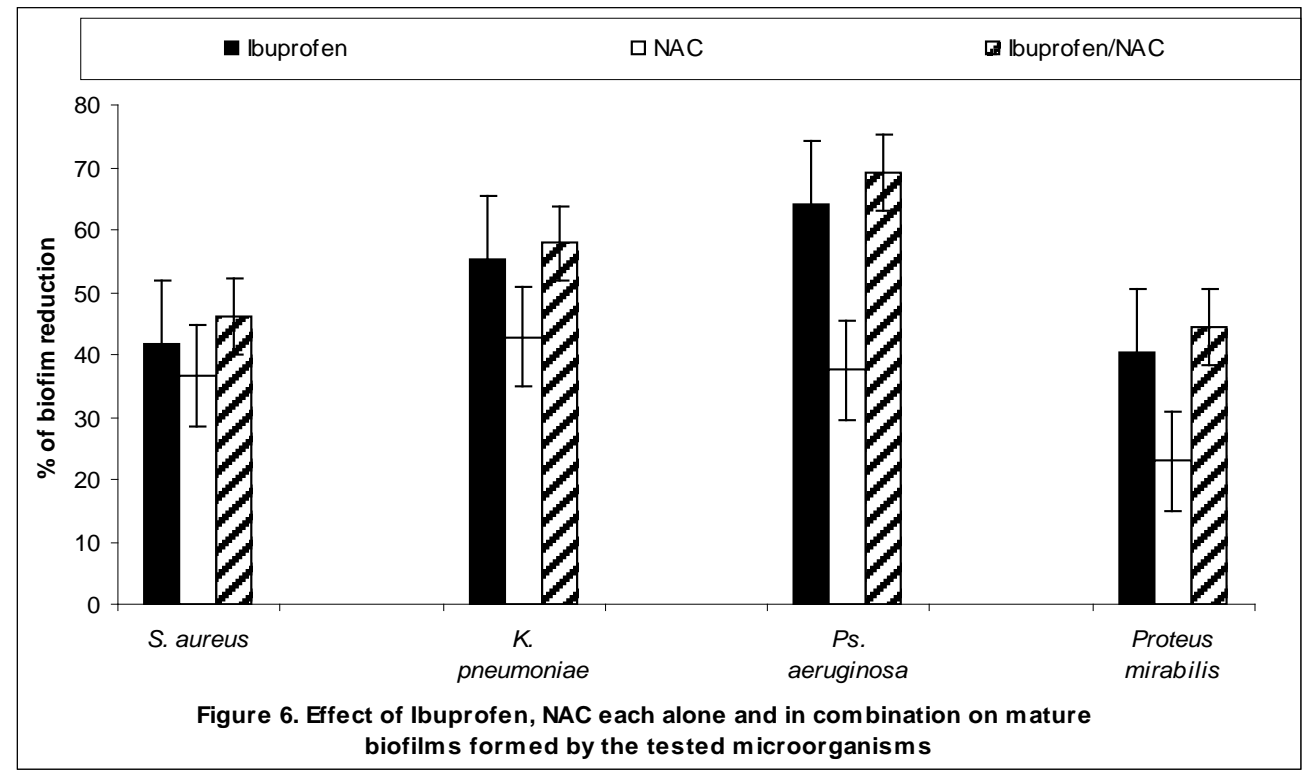

Figure 6. Effect of Ibuprofen, NAC each alone and in combination on mature biofilms formed by the tested microorganisms

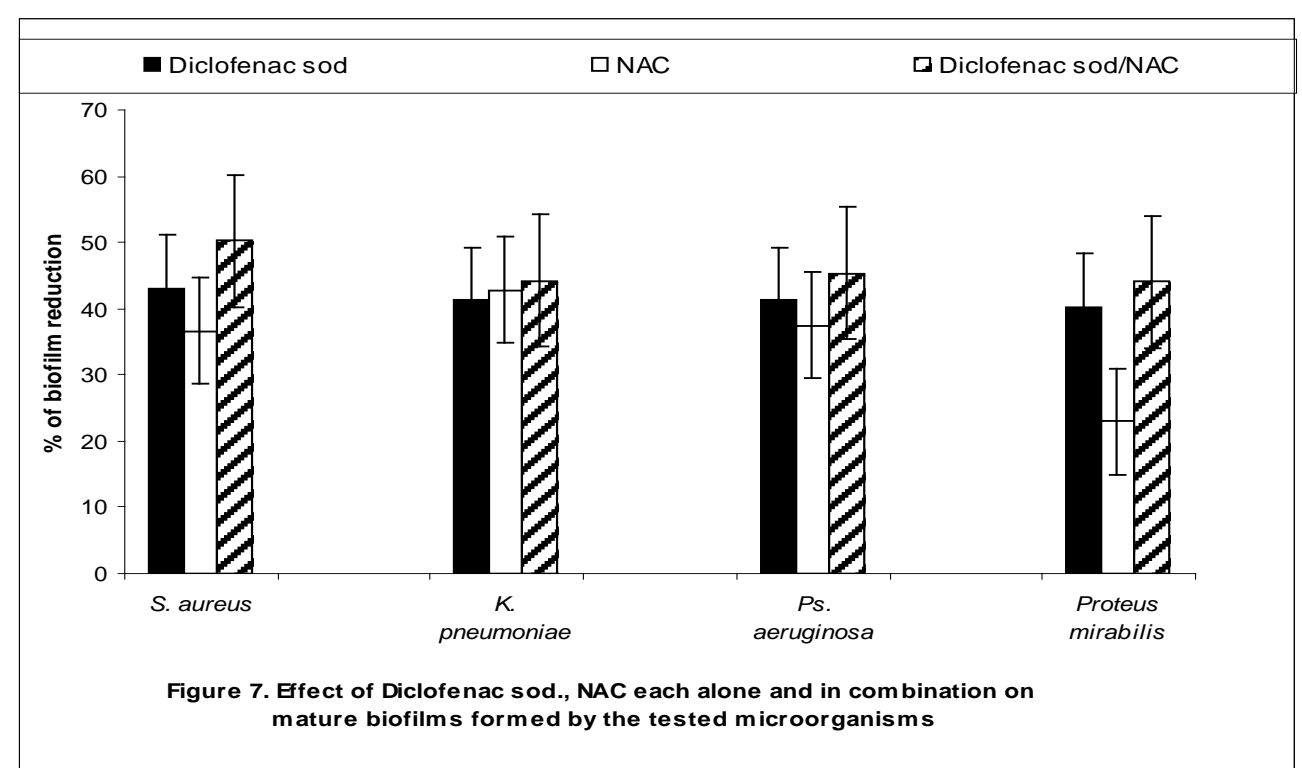

Figure 7. Effect of Diclofenac sod., NAC each alone and in combination on mature biofilms formed by the tested microorganisms 


\subsection{Effect of the Tested Compounds on Mature Biofilms Formed by the Tested Microorganisms}

Combination between NSAIDs and NAC showed the highest disruptive effect on the mature biofilms formed by the tested microorganisms. Ketoprofen and Ibuprofen had a significant disruptive effect $(\mathrm{P}<0.01)$ on all mature biofilms formed by the tested microorganisms in comparison to controls and NAC (Figure 5 and Figure 6). Sodium diclofenac had the highest disruptive effect on biofilms formed by all tested microorganisms except for $K$. pneumoniae (Figure 7). A comparison among the tested drugs in their effects on mature biofilms formed showed that ketoprofen was more potent against biofilms formed by $S$. aureus, K. pneumoniae and Proteus mirabilis but Ibuprofen was more potent against biofilm formed by Ps. aeruginosa (Figure 8).

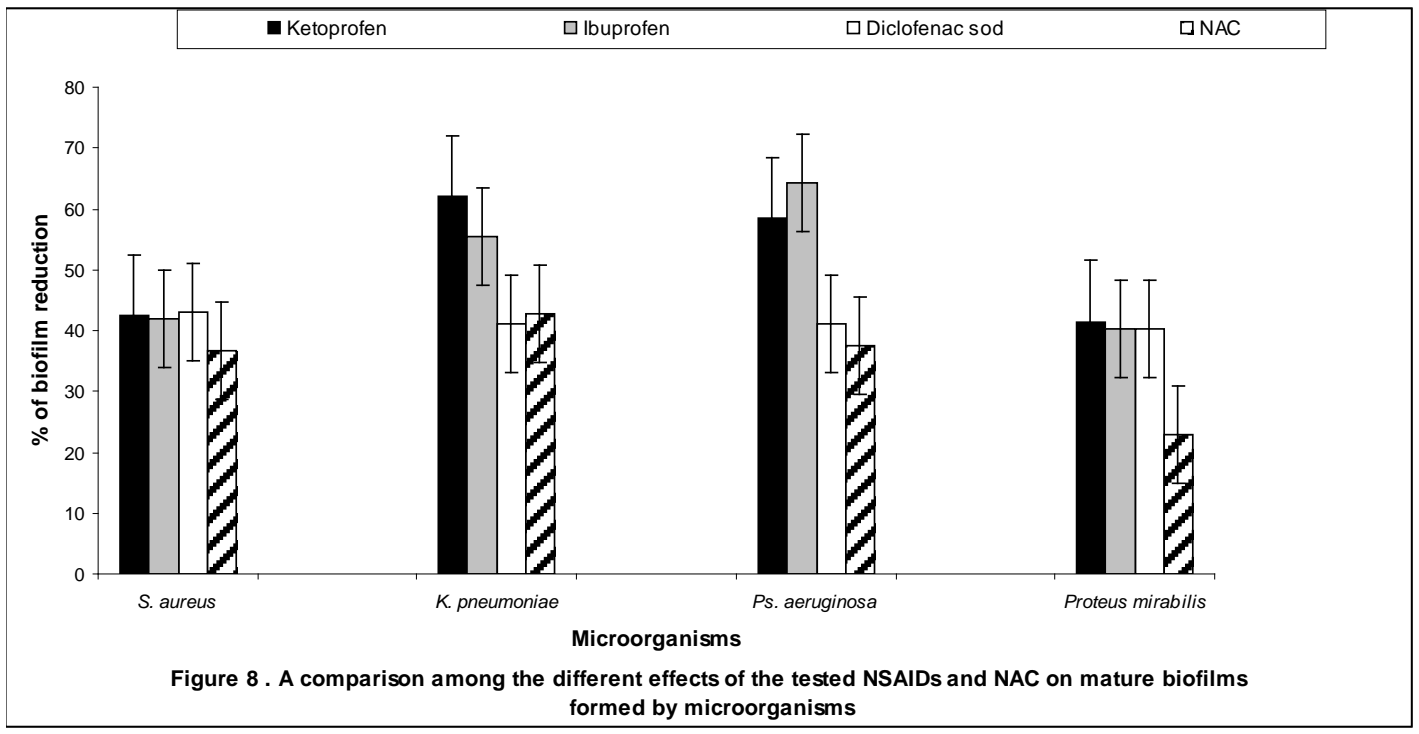

Figure 8. A comparison among the different effects of the tested NSAIDs and NAC on mature biofilms forms by microorganisms

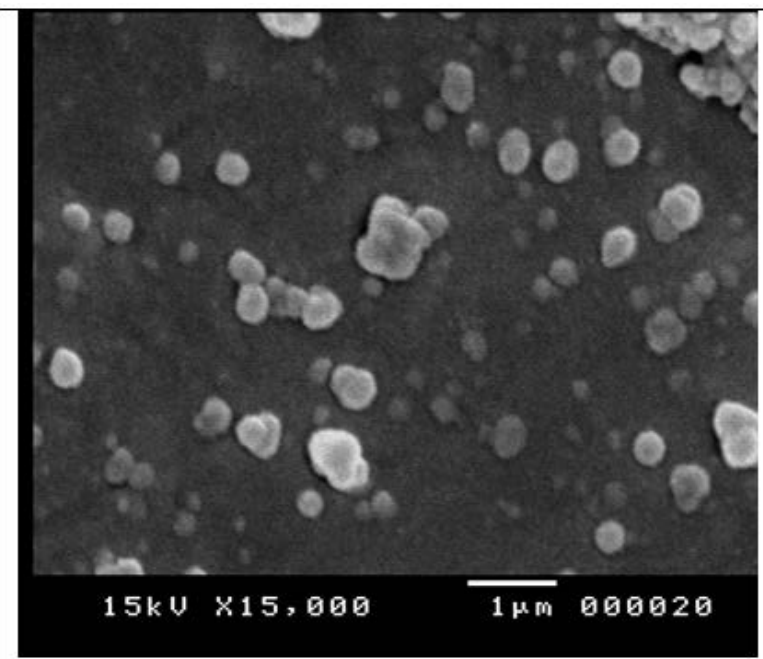

A. S. aureus (control without drugs)

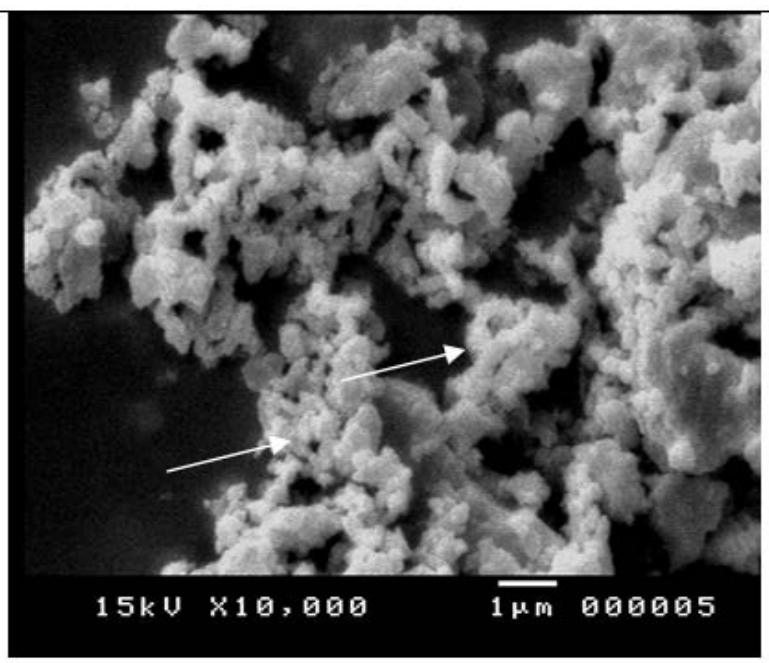

B. Effect of the diclofenac sod on $S$. aureus cells. It showed cells with disrupted membranes and appeared as a mass of cells.

Figure 9. Scanning electron micrographs showed the morphological response of S. aureus to the effect of Sodium diclofenac

\subsection{Effect of the Tested Drugs on the Morphology of Microorganisms Using SEM}

Images showed a disturbance to membranes of bacteria in the presence of Sodium diclofenac.

\subsection{Effect of the Tested Drugs on Motility of Ps. aeruginosa and Proteus mirabilis}

The tested drugs showed no effect on the motility of the tested organisms.

\section{Discussion}

Non-steroidal anti-inflammatory drugs (NSAIDs) are commonly used medicines for the management of pain and inflammation. Many studies showed that some NSAIDs have good antibacterial action especially Diclofenac sodium [31,32]. N-acetylcysteine (NAC) is a nonantibiotic drug that has antibacterial properties [34]. NAC affects several processes that are important for bacterial 
biofilm formation on stainless steel surfaces medical devices, including a drastic reduction in extracellular polysaccharide production, its ability to detach mature biofilms and thus acts as an antibiofilm substance [35].

On the other hand, Efrati et al., [25] demonstrated that NAC act as renoprotective agent against NSAIDs induced renal damage which may be due to the well-expected antioxidant effects and the augmentation of PGE2 release by renal tissue. Many studies reported that NAC increase the therapeutic activity of antibiotics. El-Rehewy et al., [36] and El-Feky et al. [37] investigated the effect of NAC ( 2 and $4 \mathrm{mg} / \mathrm{mL}$ ) in combination with ciprofloxacin (MIC and $2 \times$ MIC) against biofilm cells of several bacteria including $S$. aureus, S. epidermidis, E. coli. and others. The authors concluded that NAC potentiate the therapeutic action of ciprofloxacin. This was due to the ability of NAC to degrade the extracellular polysaccharide matrix of biofilms. As general conclusion they suggest the potential use of ciprofloxacin-NAC combination as therapeutic strategy against bacterial infections mediated by biofilms. Efrati et al., [25] reported that NAC was able of acting at the level of the matrix promoting the increasing therapeutic efficacy of vancomycin, which alone had no significant effect on cells embedded in biofilms. This activity of NAC can result in the detachment of cells, individually or in clusters, resulting in making biofilm and detached cells more susceptible to the action of other antimicrobial agents and to the immune system. Thus, the role of NAC and other antimicrobial agents targeting matrix and promoting this mechanism of detachment of cells can be an important help in the eradication of biofilms associated infections.

Our study showed that N-acetyl cysteine had a higher inhibitory effect on the adherence of $S$. aureus, $K$. pneumoniae and Proteus mirabilis in comparison to ketoprofen $(\mathrm{P}<0.05)$ and Sodium diclofenac $(\mathrm{P}<0.01)$. On the other hand, Ketoprofen showed a higher effect $(\mathrm{P}<0.05)$ on Ps. aeruginosa adherence than NAC while the tested NSAIDs were reported to have higher disruptive effect on mature biofilms more than NAC. In addition, ketoprofen had the highest effect on the inhibition of adherence of $S$. aureus, $K$. pneumoniae and $P$ s. earuginosa but ibuprofen had the highest effect against Proteus mirabilis in comparison to the tested agents. For mature biofilms, ketoprofen had the highest effect on $S$. aureus, K. pneumoniae and Proteus mirabilis but ibuprofen had the highest effect on Ps. aeruginosa. Many studies reported that Diclofenac sodium is a potent antiinflammatory, analgesic, anti-pyretic agent and in reducing the post-operative endodontic pain with less gastrointestinal side effects [37,38,39,40,41]. Diclofenac was found to show antibacterial effect against both grampositive and gram-negative bacteria and synergism with other antibiotics [42,43,44,45]. Hersh et al. [46] demonstrated the antibacterial activity of ibuprofen against six common periodontal pathogens. The exact mechanism of this antibacterial activity of diclofenac and ibuprofen is unclear. However, studies have proposed inhibition of bacterial DNA synthesis [47] or impairment of membrane activity that agree with results obtained by SEM in this study $[32,43,46,48,50,51]$. Dutta N.K. and his colleagues [45] had determinate the ability of diclofenac to protect mice from a virulent Salmonella infection. Their study had demonstrated that diclofenac (1.5-3 microg/g) protected animals from the lethality of Salmonella [45]. The time-kill curve study indicates of diclofenac comes in part, from its ability to inhibit the DNA synthesis of $E$. coli and L. monocytogenes. Diclofenac could protect murine listeriosis, salmonellosis, and tuberculosis at doses ranged within its maximum recommended human or nontoxic ex-vivo doses [48]. Although few studies found that ibuprofen and acetaminophen has significant effects to reduce some of body disorders after bacterial infection, antibacterial action of these agents are not clear for many species of pathogenic bacteria. Ibuprofen and acetaminophen were tested for antibacterial activity against seven isolates of bacteria including gram positive bacteria (Staphylococcus aureus and Bacillus subtillis) and gram negative bacteria (E. coli, Enterobacter aerogene, E. cloacae, Salmonella typhi and Paracoccus yeei) [52]. The Staphylococcus aureus and Paracoccus yeei strains were susceptible to lower concentration of ibuprofen and acetaminophen (MIC=1.25 mg/ml) and Enterobacter were resistant. The same strains were tested with diclofenac sodium, indomethacin and mefenamic acid. Diclofenac seems to be effective to inhibit the growth of bacteria in lower concentration (2.5-5 mg/ml). Staphylococcus aureus could be considered the most susceptible bacteria to diclofenac than other strains (according to disc diffusion method) [53]. Spectrophotometer assay gave much more valuable value about the inhibitory action of tested chemical agents. Diclofenac sodium also considered the powerful compound on tested bacteria. Comparing with control, the growth of all isolates was significantly reduced by $2.5 \mathrm{mg} / \mathrm{ml}$ (MIC) of diclofenac sodium. Meanwhile, Paracoccus yeei tend to be the most susceptible strain to lower level of diclofenac $(0.15-0.3 \mathrm{mg} / \mathrm{ml})$ followed by $B$. subtillis and $S$. aureus $(0.6-1.25 \mathrm{mg} / \mathrm{ml})[54]$. In another study, aspirin or ibuprofen was administered to mice undergoing treatment of tuberculosis infection (Mycobacterium tuberculosis) to determine if these non-steroidal anti-inflamatory drugs enhance pyrazinamide activity in vivo [55]. Simultaneous administration of either aspirin or ibuprofen with pyrazinamide resulted in a further decrease of about 0.4 $\log _{10} \mathrm{CFU}$ in the lung and more than $1 \log _{10} \mathrm{CFU}$ in the spleen compared with mice receiving pyrazinamide alone. Aspirin and ibuprofen enhance the effect of pyrazinamide during the initial phase of tuberculosis treatment in the mouse model. The antimicrobial ability of diclofenac sodium, indomethacin and mefenamic acid to eliminate pathogenic organisms is not limited with direct inhibitory action of those organisms, but also includes indirect effects by using the main function of such compounds as anti-inflammatory to facilitate the destruction of affected organisms. In meningitis patients, diclofenac sodium and indomethacim reduce the inflammation resulted from infection with bacterial meningitis [56].

\section{Conclusion}

The impact of NSAIDs on adhesion and bacterial biofilm formation leads us to say that administration of the drugs in post-surgical period may lead to decrease the infection risk.

Many studies showed that NSAIDs act synergistically with antibiotics, so application of these drugs in perioperative period may increase the effectiveness of antibiotics 
applied for prophylactic purposes NAC showed more significant effect on the adherence than the tested NSAIDs while NSAIDs showed more disruptive effect than NAC against mature biofilms. NSAIDs and NAC combination showed increased activity and a higher effect than the effect of each alone.

\section{Acknowledgment}

This study was supported by Supporting of Excellence Students (SESP) Projects, Egyptian Ministry of Higher Education, Egypt.

\section{References}

[1] Pettit RK, Weber CA, Kean MJ, et al. Microplate Alamar Blue assay for Staphylococcus epidermidis biofilm susceptibility testing. Antimicrob Agents Chemother. 2005, 49: 2612-2617.

[2] Flemming K, Klingenberg C, Cavanagh JP, et al. High in vitro antimicrobial activity of synthetic antimicrobial peptidomimetics against staphylococcal biofilms. J Antimicrob Chemother. 2009, 63: 136-145.

[3] Lindsay D, von Holy A. Bacterial biofilms within the clinical setting: what healthcare professionals should know. J Hosp Infect. 2008, 64: 313-325.

[4] Donlan RM, Costerton JW. Biofilms: survival mechanisms of clinically relevant microorganisms. Clin Microbiol Rev 2002, 15: 167-193.

[5] Chambers ST, Peddie B, Pithie A. Ethanol disinfection of plasticadherent micro organisms. J Hosp Infect. 2006, 63: 193-196.

[6] Frank KL, Reichert EJ, Piper KE, Patel R. In vitro effects of antimicrobial agents on planktonic and biofilm forms of Staphylococcus lugdunensis clinical isolates. Antimicrob Agents Chemother. 2007, 51: 888-895.

[7] Gualtieri M, Bastide L, Villain-Guillot P, Michaux-Charachon S, Latouche J, Leonetti JP. In vitro activity of a new antibacteria rhodanine derivative against Staphylococcus epidermidis biofilms. $J$ Antimicrob Chemother. 2006, 58: 778-783.

[8] Jefferson KK. What drives bacteria to produce a biofilm? FEMS Microbiol Lett 2004; 236: 163-173.

[9] Prüß BM, Besemann C, Denton A, Wolfe J. A complex transcription network controls the early stages of biofilm development by Escherichia coli. J Bacteriol. 2006, 188: 37313739.

[10] An YH, Friedman RJ. Concise review of mechanisms of bacterial adhesion to biomaterial surfaces. J Biomed Mater Res. 1998, 43: 338-348.

[11] Katsikogianni M, Missirlis YF. Concise review of mechanisms of bacterial adhesion to biomaterials and of techniques used in estimating bacteriaematerials interactions. Euro Cell Mater. 2004, 8: 37-57.

[12] Cerca B, Martins S, Pier G, Oliveira R, Azevedo J. The relationship between inhibition of bacterial adhesion to a solid surface by sub-MICs of antibiotics and subsequent development of a biofilm. Res Microbiol. 2005, 156: 650-655.

[13] Kinnari TJ, Peltonen LI, Kuusela P, Kiviahti J, Kononen M, Jero J. Bacterial adherence to titanium surface coated with human serum albumin. Otol Neurotol. 2005, 26: 380-384.

[14] Kleinknecht D, Landais P, Goldfarb B. Analgesic and nonsteroidal anti-inflammatory drug-associated acute renal failure: a prospective collaborative study. Clin Nephrol. 1986, 25: 275-281.

[15] Oates JA, FitzGerald GA, Branch RA, Jackson EK, Knapp HR, Roberts LJ. Clinical implications of prostaglandin and thromboxane A2 formation (2). N Engl J Med. 1988, 319: 761-767.

[16] Patrono C, Dunn MJ. The clinical significance of inhibition of renal prostaglandin synthesis. Kidney Int. 1987, 32: 1-12.

[17] Huerta C, Castellsague J, Varas-Lorenzo C, Garcia Rodriguez LA. Nonsteroidal anti-inflammatory drugs and risk of ARF in the general population. Am J Kidney Dis. 2005, 45: 531-539.

[18] Efrati S, Averbukh M, Berman S et al. N-Acetylcysteine ameliorates lithium-induced renal failure in rats. Nephrol Dial Transplant. 2005, 20: 65-70.
[19] Efrati S, Dishy V, Averbukh $\mathrm{M}$ et al. The effect of Nacetylcysteine on renal function, nitric oxide, and oxidative stress after angiography. Kidney Int. 2003, 64: 2182-2187.

[20] Feldman L, Efrati S, Dishy V et al. N-acetylcysteine ameliorates amphotericin-induced nephropathy in rats. Nephron Physiol. 2005, 99: 23-27.

[21] DiMari J, Megyesi J, Udvarhelyi N, Price P, Davis R, Safirstein R. $\mathrm{N}$-acetyl cysteine ameliorates ischemic renal failure. Am J Physiol. 1997, 272: F292-F298.

[22] Mazzon E, Britti D, De Sarro A, Caputi AP, Cuzzocrea S. Effect of $\mathrm{N}$-acetylcysteine on gentamicin-mediated nephropathy in rats. Eur J Pharmacol, 2001, 424: 75-83.

[23] Marenzi G, Assanelli E, Marana I et al. N-acetylcysteine and contrast-induced nephropathy in primary angioplasty. $N$ Engl $J$ Med 2006; 354: 2773-2782.

[24] Heyman SN, Goldfarb M, Shina A, Karmeli F, Rosen S. Nacetylcysteine ameliorates renal microcirculation: studies in rats. Kidney Int 2003, 63: 634-641.

[25] Efrati S, Berman S, Siman-Tov Y, Lotan R, Averbukh Z, Weissgarten J and Golik A. $N$-acetylcysteine attenuates NSAIDinduced rat renal failure by restoring intrarenal prostaglandin synthesis Nephrol Dial Transplant. 2007, 22: 1873-1881.

[26] Christensen G.D., W.A. Simpson, J.A. Younger, L.M. Baddour, F.F. Barrett, D.M. Melton, et al. Adherence of coagulase negative Staphylococci to plastic tissue cultures: a quantitative model for the adherence of staphylococci to medical devices. J. Clin. Microbiol. 1985, 22: 996-1006.

[27] Bennet J.V., Brodie J.L., Benner J.L., Kirby W.M.M., "Simplified accurate method for antibiotic assay of clinical specimens". Appl Microbiol. 1966, 14: p. 2170-2177.

[28] Xiaogang L, Zhun Y and Jianping X. Quantitative variation of biofilms among strains in natural populations of Candida albicans. Microbiology 2003, 149: 353-362.

[29] Soboh F, Khoury AE, Zamboni AC, Davidson D, Mittelman MW. Effects of ciprofloxacin and protamine sulfate combinations against catheter-associated Pseudomonas aeruginosa biofilms. Antimicrob. Agents Chemother 1995, 39: 1281-1286.

[30] Wojnicz D, Tichaczek-Goska D. Effect of sub-minimum inhibitory concentrations of ciprofloxacin, amikacin and colistin on biofilm formation and virulence factors of Escherichia coli planktonic and biofilm forms isolated from human urine. BJM 44, 1, 259-265 (2013).

[31] Wang WH, Wong WM, Dailidiene D, Berg DE, Gu Q, Lai KC et al. Aspirin inhibits the growth of Helicobacter pylori and enhances its susceptibility to antimicrobial agents. Gut. 2003 Apr; 52(4): 490-5.

[32] Hersh EV, Hammond BF, Fleury AA. An-timicrobial activity of flurbiprofen and ibupro-fen in vitro against six common periodontal pathogens. J Clin Dent. 1991, 3(1): 1-5.

[33] Olofsson AC, Hermansson M, Elwing H. N-acetyl-l-cysteine affects growth, extracellular polysaccharide production and bacterial biofilm formation on solid surfaces. Appl. Environ. Microb. 2003, 69: 4814-22.

[34] Perez-Giraldo C, Rodriguez-Benito A, Moran FJ, Hurtado C, Blanco MT, Gómez-García AC. Influence of N-acetylcysteine on the formation of biofilm by Staphylococcus epidermidis. J Antimicrob chemoth. 1997, 39: 643-6.

[35] Abbas Hisham A., Fathy M. Serry, Eman M. EL-Masry (2012) Combating Pseudomonas aeruginosa Biofilms by Potential Biofilm Inhibitors Asian J. Res. Pharm. Sci. 2012, Vol. 2: 66-72.

[36] El-Rehewy M S K, El-Feky M A, Hassan MA, Abolella H A, Abolyosr A, Abd El-Baky R M and Gad G F In vitro Efficacy of Ureteral Catheters Impregnated with Ciprofloxacin, N acetylcysteine and their Combinations on Microbial Adherence Clinical Medicine: Urology 2009, 21-8.

[37] El-Feky, M.A., El-Rehewy, M.S., Hassan, M.A., Abolella H.A., Abd El-Baky, R.M., and Gad, G.F. (2009). Effect of ciprofloxacin and $\mathrm{N}$-acetylcysteine on bacterial adherence and biofilm formation on ureteral stent surfaces. Pol. J. Microbiol., 58(3), pp. 261-267.

[38] Scholer DW, Boettcher I, Ku EC, Schweizer A. Pharmacology of diclofenac so-dium (Voltaren). Semin Arthritis Rheum. 1985, 15(2 Suppl 1): 61-4.

[39] Zuniga JR, Malmstrom H, Noveck RJ, Campbell JH, Christensen S, Glickman RS, et al. Controlled phase III clinical trial of diclofenac potassium liquid-filled soft gelatin cap-sule for treatment of postoperative dental pain. J Oral Maxillofac Surg. 2010, 68(11): 2735-42. 
[40] Kubitzek F, Ziegler G, Gold MS, Liu JM, Ionescu E. Analgesic efficacy of low-dose dic-lofenac versus paracetamol and placebo in postoperative dental pain. J Orofac Pain. 2003 Summer; 17(3): 237-44.

[41] Buyukkurt MC, Gungormus M, Kaya O. The effect of a single dose prednisolone with and without diclofenac on pain, trismus, and swelling after removal of mandibular third molars. $J$ Oral Maxillofac Surg. 2006, 64(12): 1761-6.

[42] Saatchi M, Mosavat F, Razmara F, Soley-mani B. Comparison of the effect of Ibuprofenand slow-released Diclofenac Sodium in con-trolling post endodontic pain. J Dent Tehran Uni Med Sci. 2010, 22: 185-91.

[43] Negm MM. Effect of intracanal use of nonsteroidal antiinflammatory agents on post-treatment endodontic pain. Oral Surg Oral Med Oral Pathol. 1994, 77(5): 507-13.

[44] Kristiansen JE, Hendricks O, Delvin T, Butterworth TS, Aagaard $\mathrm{L}$, Christensen JB, et al. Reversal of resistance in microorganisms by help of non-antibiotics. J Antimicrob Che-mother. 2007, 59(6): 1271-9.

[45] Dutta NK, Mazumdar K, Seok SH, Park JH. The antiinflammatory drug Diclofenac retains antilisterial activity in vivo. Lett Appl Microbiol. 2008, 47(2): 106-11.

[46] Dutta NK, Mazumdar K, Dastidar SG, Park JH. Activity of diclofenac used alone and in combination with streptomycin against Mycobacterium tuberculosis in mice. Int $J$ Anti-microb Agents. 2007, 30(4): 336-40.

[47] Dutta NK, Kumar KA, Mazumdar K, Das-tidar SG. In vitro and in vivo antimycobacteri-al activity of antiinflammatory drug, diclofenac sodium. Indian J Exp Biol. 2004, 42(9): 922-7.
[48] Dutta NK, Annadurai S, Mazumdar K, Dastidar SG, Kristiansen JE, Molnar J, et al. Potential management of resistant microbial infections with a novel non-antibiotic: the anti-inflammatory drug diclofenac sodium. Int J Antimicrob Agents. 2007 Sep; 30(3): 2429.

[49] Dastidar SG, Ganguly K, Chaudhuri K, Chakrabarty AN. The antibacterial action of diclofenac shown by inhibition of DNA synthesis. Int J Antimicrob Agents. 2000, 4(3): 249-51.

[50] Negm MM. Intracanal use of a corticosteroid-antibiotic compound for the management of post treatment endodontic pain. Oral Surg Oral Med Oral Pathol Oral Radiol Endod. 2001, 92(4): 435-9.

[51] Ehrmann EH, Messer HH, Adams GG. The relationship of intracanal medicaments to postoperative pain in endodontics. Int Endod J. 2003, 36(12): 868-75.

[52] Mazumdar K. Dastidar S.G., Park J. H., et al. The anti-infl amatory non-antibiotic helper compound diclofenac: an antibacterial drug target. Eur. J. Clin. Microbiol. Infect. Dis. 2009. 28 (8) 881-891.

[53] AL-Janabi A.S. In vitro antibacterial activity of ibuprofen and acetaminophen. J. Global Infect. Dis. 2010. 2. 105-108.

[54] AL-Janabi A.S. Comparison of disc diffusion assay with spectrophotometer technique for antibacterial activity of diclofenac sodium, indomethacin and mefenamic acid. Asian $J$. Pharm. 2009. 3: 148-52.

[55] Byrne S.T., Denkin S.M., Zhang Y. Aspirin and ibuprofen enhance pyrazinamide treatment of murine tuberculosis. J.Antimicrob. Chemother. 2006, 59. 313-316.

[56] Van der Flier M., Geelen S.P., Kimpen J.L. Anti-infl ammatory adjuvant agents in bacterial meningitis. Curr. Med. Chem. 2002, 1 . 55-62. 